\title{
BMJ Open Unwanted effects of treatments for depression in children and adolescents: a mapping of systematic reviews
}

\author{
Lise Mette Eidet (iD , Astrid Dahlgren, Mari Elvsåshagen
}

To cite: Eidet LM, Dahlgren A, Elvsåshagen $M$. Unwanted effects of treatments for depression in children and adolescents: a mapping of systematic reviews. BMJ Open 2020;10:e034532. doi:10.1136/ bmjopen-2019-034532

- Prepublication history and additional material for this paper are available online. To view these files, please visit the journal online (http://dx.doi. org/10.1136/bmjopen-2019034532).

Received 25 September 2019 Revised 10 December 2019 Accepted 28 January 2020

Check for updates

(C) Author(s) (or their employer(s)) 2020. Re-use permitted under CC BY-NC. No commercial re-use. See rights and permissions. Published by BMJ.

Section for Evidence Review, Research Support and Communication, RBUP, 0slo, Norway

Correspondence to Lise Mette Eidet; lise.eidet@r-bup.no

\begin{abstract}
Objectives To describe the results of a mapping review exploring the coverage of unwanted treatment effects in systematic reviews of the effects of various treatments for moderate to severe depression in children and adolescents.

Setting Any context or service providing treatment for depression, including interventions delivered in local communities and school settings, as well as services provided in primary or specialist care.
\end{abstract}

Participants Children and young people with moderate to severe depression ( $<18$ years).

Interventions Systematic reviews published in 2011 or later comparing the effects of any treatment for children and adolescents with moderate to severe depression meeting the Database of Abstracts of Reviews of Effects criteria. The systematic search was performed in April 2018 and updated in December 2018.

Primary outcomes Any unwanted effects of treatments as defined in the systematic review.

Results We included 10 systematic reviews covering 19 treatment comparisons. Unwanted effects were assessed for seven of 19. Three comparisons were evaluations of pharmaceutical interventions or combination therapy, reporting effects on 'suicidal ideation' and 'suicide risk'. Two included therapy, reporting 'self-harm', and 'suicidal ideation', and two comparisons included transcranial magnetic stimulation and electroconvulsive treatment. Unwanted effects evaluated for these treatments were mostly symptoms of physical discomfort such as headache or cramps. For the remaining treatment comparisons evaluating psychological and psychosocial therapies, unwanted effects were not evaluated or found. A limitation of overviews of systematic reviews such as this mapping study is that data extraction is done based on the reporting of results by the review authors and not on the primary studies.

Conclusion The unwanted effects of widely used treatments for children and young people with depression is unknown. This is a major barrier for evidence informed decision making about treatment choices for children and young people. We suggest that unwanted effects should be a reporting standard in all protocols describing evaluations of treatments, including primary studies as well as systematic reviews.

\section{INTRODUCTION}

Depression is a serious mood disorder that affects about $10 \%$ of the world population. ${ }^{1}$

\section{Strengths and limitations of this study}

A mapping review is an appropriate first step in identifying research gaps.

- To our knowledge, this is the first mapping review to explore occurrence and type of unwanted effects evaluated in systematic reviews on the effects for young people with depression.

- We have used systematic and transparent review methods, including only up-to-date systematic reviews.

- Our data extraction is based on the reporting of results by the review authors, thus primary studies may have evaluated other unwanted effects.

- Whether the problem is at the primary study level or in the execution of systematic reviews, their absence in systematic reviews is of major importance because of the reliance now placed on systematic reviews by practitioners and guideline developers.

It is associated with social and educational impairments and can predict suicide, selfharm and poor physical health. Depression can also mark the beginning of long-term mental health difficulties. ${ }^{2}$

Depression in children and adolescents can be treated in several ways. The most commonly used treatment options are psychological, psychosocial and pharmaceutical treatments. The large variety of therapeutic interventions give rise to questions of clinical effectiveness and side effects. ${ }^{2}$

Systematic reviews provide the most reliable evidence base for making informed treatment choices. Evidence summaries should also serve as a starting point when launching new research, such as the development of measures or evaluation tools. ${ }^{3-5}$ Knowledge about the benefits and harms associated with treatments is essential for informed decision making and should be integrated with the practitioner's personal experience and through dialogue with the patient. ${ }^{367}$ All treatments believed to be beneficial can also be harmful. ${ }^{8}$ Any action to improve an outcome, whether psychological, dietary, 
self-help groups or medication can also have unwanted effects, such as adverse events or reactions, harms, negative effects, toxicity or complications. ${ }^{9}$

Health and welfare services have sometimes failed to recognise the harms of some interventions. Although interventions are well-intentioned, systematic research has identified serious harmful effects; examples includes thalidomide for morning sickness in pregnant women that led to fetus malformations in the $1960 \mathrm{~s},{ }^{10}$ the advice of baby sleeping on stomach before the 1990s even though evidence that it was harmful and led to the sudden infant death syndrome was available from the $1970 \mathrm{~s},{ }^{11}$ and the 'Scared Straight' crime prevention programme that likely had an opposite effect than intended and harmed the youths and increased delinquency relative to doing nothing. ${ }^{12}$ It has also been reported that group treatment for self-harm, depression and suicidal ideation has sometimes been followed by an increase in self harm. ${ }^{13}$

Professionals have a responsibility to convey to patients the known benefits and harms associated with treatments and also if there are known uncertainties associated with treatment effects. ${ }^{4}$ Such uncertainties result from lack of research or that the evidence supporting the treatment is weak. ${ }^{4}$ Identifying evidence gaps in the existing literature should also be the starting point for new research initiatives and shaping future research priorities (EBRNetwork. org). The purpose of a mapping review is to describe a research field by finding and systematising existing literature. ${ }^{5}$ It is also essential for identifying knowledge gaps and suggesting new research priorities. An overview of evaluations of potential unwanted effects associated with treatments for children and young people with depression should help to support patients, practitioners and researchers in making informed decisions.

\section{Objective}

This study aims to map the occurrence of evaluations of unwanted effects in systematic reviews of the effects of various treatments for moderate to severe depression in children and adolescents. We will also describe which treatment comparisons included assessments of unwanted effects and report how these outcomes were evaluated.

\section{METHODS}

We have recently developed an evidence portal for the Norwegian service providers and the general public summarising research assessing the effects of treatments for young people with mental illness. ${ }^{14}$ The evidence portal has been developed according to national and international standards for systematic reviews and guideline development. ${ }^{15-18}$ This work gives an opportunity to map reviews analysing methodological issues in the available evidence. This mapping review is a secondary analysis based on the evidence portal and our previous work summarising the effects of treatments for children and youth with depression. ${ }^{19}$

\section{Description of study design and search strategy}

According to the typology of Grant and Booth, ${ }^{5}$ a mapping review differs from other scoping assessments. ${ }^{8}$ Whereas a scoping review is usually restricted to a systematic, criterial-led sorting of the results of a literature search according to a set of criteria, the objective of a mapping review is to quantify, describe and organise the literature according to theoretical perspectives or by population or other characteristics. ${ }^{5}$ For many researchers, this is the first stop to get an overview over a research field before imitating new research efforts. It is not intended to be used for evaluating the effects of a treatment. For this mapping review, we included all systematic reviews evaluating the effects of treatments for children and young people under 18 for any psychological, pharmaceutical or other relevant forms of treatment such as social interventions, physical activity or nutrition.

The evidence portal and consequently our search for studies for this mapping review was largely based on IN SUM: A database of systematic reviews on effects of child mental health and welfare interventions (www. insum.no). ${ }^{20}$ The search was performed in April 2018 and updated in December 2018. IN SUM is a recently developed database of systematic reviews on the effects of interventions relevant to children and young people's mental health and welfare. The database indexes systematic reviews from the following databases: Cochrane Database of Systematic Reviews, Campbell Library, PsycINFO, Medline, Embase, Web of Science, Database of Abstracts of Reviews of Effects (DARE) and Evidence-Based Mental Health. Online supplementary appendix 1 describes the search strategy of IN SUM. We reviewed all 1153 records in IN SUM for this study. Two authors independently screened all references, extracting all reviews potentially meeting our inclusion criteria (see table 1). In addition to IN SUM, we also hand searched the websites of the Norwegian Institute for Public Health, the Swedish Agency for Health Technology Assessment and Assessment of Social Services, the Danish Health Authority for Systematic Reviews and the National Institute for Health and Care Excellence for evidence-based guidelines.

Reviews included in IN SUM, and consequently this mapping review, must adhere to the DARE criteria to be considered a systematic review. ${ }^{21}$ According to these criteria the review authors must provide:

1. Clear inclusion and exclusion criteria.

2. A comprehensive search strategy.

3. A compilation of results from included studies.

4. Quality assessment of included studies.

Furthermore, we only included systematic reviews published 2011 or later. This cut-off is pragmatic and based on a consideration that a review published earlier than this is obsolete and no longer a reliable basis for evidence and in need for being updated.

There is a high number of systematic reviews and guidelines available. In case of overlap between these systematic reviews, we based our prioritisation on the principles of quality and the review's date of search. 
Table 1 Inclusion criteria for search and retrieval by research design: systematic reviews and evidence-based guidelines

\begin{tabular}{|c|c|}
\hline Design & Systematic reviews and evidence-based guidelines. \\
\hline Populations & $\begin{array}{l}\text { Children and adolescents from } 0 \text { to } 18 \text { years old with moderate to severe depression (as defined by } \\
\text { the review authors). }\end{array}$ \\
\hline Types of interventions & $\begin{array}{l}\text { Psychological, medical and other relevant treatments such as social interventions, physical activity } \\
\text { or nutrition. }\end{array}$ \\
\hline Comparison & Other relevant interventions, treatment as usual or no intervention. \\
\hline Outcomes & Unwanted effects of psychological treatments for depression. \\
\hline Date & Published 2011 or later. \\
\hline Quality & DARE criteria $1-4$. \\
\hline
\end{tabular}

DARE, Database of Abstracts of Reviews of Effects.

We excluded reviews that did not meet the criteria mentioned above, only addressed adult patients or other patients with primary diagnoses other than depression. Preventive interventions were not included.

\section{Data collection and presentation of the findings}

Unwanted effects or symptoms is defined as unwanted experiences in participants (unfavourable changes in health), which may or may not be caused by treatments. ${ }^{22}$ We mapped all types of unwanted effects reported in the systematic reviews. These were sorted by treatment comparison and entered into an Excel spreadsheet for analysis. We also extracted information about how these effects were assessed (ie, the outcome measurements used). One of us extracted this information and another quality checked the first author's judgements. We considered measures of self-harm to be unwanted effects, although self-harm could also be part of the symptomology associated with depression. For this outcome,

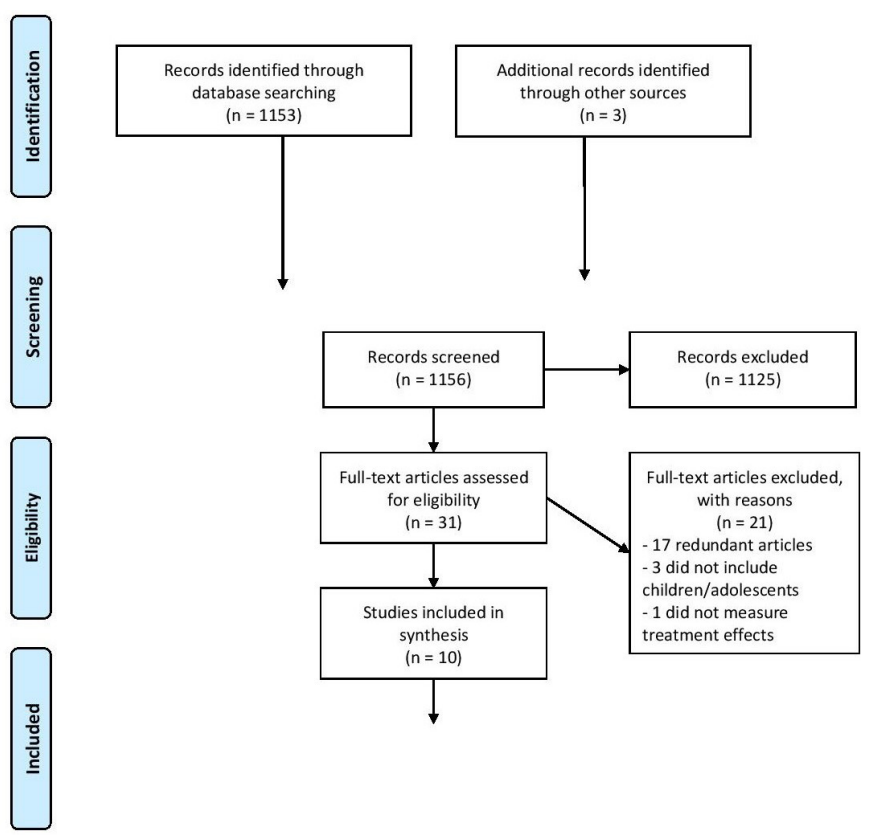

Figure 1 Preferred Reporting Items for Systematic Review and Meta-Analysis flow diagram. we also report the review authors' rationale for including this outcome.

Loss to follow-up may be associated with unwanted effects but may also be due to other reasons. For this review we did not consider this as an unwanted effect.

\section{Patient and public involvement}

No patients were involved in conducting this mapping review.

\section{RESULTS \\ Description of the included studies}

We screened 1153 references indexed in IN SUM (the hand search of the other databases resulted in three additional publications). Of the 1153 references, 1125 were excluded in the initial screening. Thirty-one articles were assessed in full text for eligibility (see the Preferred Reporting Items for Systematic Review and Meta-Analysis flow diagram in figure 1). Ten reviews (see online supplementary appendix 2) evaluating 19 treatment comparisons met our inclusion criteria.

After finalising our mapping review, two additional reviews were identified with potential relevance to this analysis. $^{23} 24$

\section{Treatment comparisons evaluated in the included reviews}

Of 19 treatment comparisons, the reviews reported unwanted effects in seven (see table 2). Three of these seven were associated with a drug treatment or combination therapy, one evaluated unwanted effects of electroconvulsive therapy (ECT) and one evaluated unwanted effects of transcranial magnetic stimulation (rTMS). Two comparisons included therapy. See table 3 for instruments used for measuring unwanted effects.

The unwanted effects measured were 'suicidal ideation', 'suicidal risk', 'self-harm' and 'suicide', ${ }^{25-27}$ 'tension headache', 'scalp discomfort', 'sleepiness' and 'hypomania' after TMS $^{27}$ and 'discomfort', headache', 'memory loss' and 'cramps' after ECT. ${ }^{25}$

The treatment comparisons in which no unwanted effects were identified included evaluations of cognitive 
Table 2 Treatment comparisons evaluated in the included reviews

\begin{tabular}{|c|c|c|}
\hline Study identification & Comparison of treatments & Unwanted effects \\
\hline \multicolumn{3}{|c|}{ Moderate and severe depression } \\
\hline Aalbers et $a /^{30}$ & Music therapy versus cognitive behavioural therapy & No results identified \\
\hline Bailey et $a^{29}$ & $\begin{array}{l}\text { Physical activity versus treatment as usual, waitlist and attention/ } \\
\text { activity placebo condition }\end{array}$ & No results identified \\
\hline Cook et $a l^{26}$ & $\begin{array}{l}\text { Dialectical behavioural therapy versus treatment as usual or no follow- } \\
\text { up }\end{array}$ & Self-harm \\
\hline Fleming $^{28}$ & Serious games versus treatment as usual or no follow-up & No results identified \\
\hline Meekums et $\left.a\right|^{31}$ & Dance movement therapy versus treatment as usual or no follow-up & No results identified \\
\hline Pu et $\left.a\right|^{34}$ & Interpersonal psychotherapy versus treatment as usual or no follow-up & No results identified \\
\hline Tindall et $a^{39}$ & $\begin{array}{l}\text { Behavioural activation versus treatment as usual, waitlist or no follow- } \\
\text { up }\end{array}$ & No results identified \\
\hline Socialstyrelsen ${ }^{25}$ & Psychoeducation versus treatment as usual or waitlist & No results identified \\
\hline Socialstyrelsen ${ }^{25}$ & Cognitive behavioural therapy versus treatment as usual or no follow-up & No results identified \\
\hline Socialstyrelsen ${ }^{25}$ & Interpersonal therapy versus cognitive behavioural therapy & No results identified \\
\hline Socialstyrelsen ${ }^{25}$ & Psychodynamic therapy versus systemic family therapy & No results identified \\
\hline Socialstyrelsen ${ }^{25}$ & Systemic family therapy compared with individual or other therapy & No results identified \\
\hline Socialstyrelsen ${ }^{25}$ & Attachment-based family therapy versus no follow-up & Suicidal ideation \\
\hline Socialstyrelsen ${ }^{25}$ & $\begin{array}{l}\text { Mindfulness based interventions versus treatment as usual or no follow- } \\
\text { up }\end{array}$ & No results identified \\
\hline Dalsbø et $\left.a\right|^{33}$ & Combination treatment versus psychological treatment & Suicidal ideation \\
\hline Socialstyrelsen ${ }^{25}$ & Medical treatment versus psychological treatment & Suicidal ideation \\
\hline \multicolumn{3}{|c|}{ Serious and treatment resistant depression } \\
\hline Donaldson et $\left.a\right|^{27}$ & Transcranial magnetic stimulation & $\begin{array}{l}\text { Tension headache, scalp } \\
\text { discomfort, sleepiness, } \\
\text { hypomania and seizure }\end{array}$ \\
\hline Socialstyrelsen ${ }^{25}$ & Electroconvulsive therapy & $\begin{array}{l}\text { Discomfort, headache, } \\
\text { memory loss, cramps }\end{array}$ \\
\hline Socialstyrelsen ${ }^{25}$ & Combination treatment versus psychological treatment alone & Suicide risk \\
\hline
\end{tabular}

behavioural therapy, ${ }^{25}$ interpersonal psychotherapy, ${ }^{25}$ psychodynamic therapy, ${ }^{25}$ systemic family therapy, ${ }^{25}$ mindfulness-based interventions, ${ }^{25}$ serious games, ${ }^{28}$ physical activity, ${ }^{29}$ music therapy ${ }^{30}$ and dance movement therapy. ${ }^{31}$

The drug treatments covered included fluoxetine, paroxetine, sertraline and escitalopram.

\section{DISCUSSION}

\section{Summary of findings}

Overall, unwanted effects were reported for less than a third of the treatment comparisons. Of the seven comparisons that did include a potential measure of unwanted effects, three evaluated the effects of pharmacological interventions, with suicidal ideation and suicidal risk being the unwanted effects measured. However, the rationale for evaluating these outcomes may have been twofold; as drug treatment for depression theoretically may both reduce and increase the risk of suicidal behaviour. Whereas previous research has suggested that drug treatment for young people with depression may increase suicidal risk, such behaviour may also be associated with depression itself. ${ }^{32}$

'Self-harm' was measured as a part of the symptomatology in the comparison 'dialectical behavioural therapy versus treatment as usual or no follow-up' by Cook et $a l^{26}{ }^{26}$ Socialstyrelsen ${ }^{25}$ measured 'suicidal ideation' from baseline to follow-up as a part of the symptomatology in the comparison 'attachment-based behavioural therapy versus no follow-up'. The five other comparisons (see tables 2-3) by Socialstyrelsen, ${ }^{25}$ Donaldson et $a l^{27}$ and Dalsbø $e t a l^{33}$ considered the outcomes 'suicidal ideation', 'suicide risk', 'discomfort', 'headache', 'memory loss', 'cramps', 'scalp discomfort', 'sleepiness', 'hypomania' and 'seizure' to be specific measures of unwanted effects.

Psychological therapy and other interventions can be effective in reducing depression. ${ }^{192534}$ However, our findings suggest that unwanted effects are seldom reported in systematic reviews for these young patients, particularly with respect to non-pharmaceutical interventions. This may be explained by less strict reporting guidelines for non-pharmacological interventions and because 
Table 3 Instruments used for measuring unwanted effects

\begin{tabular}{|c|c|c|}
\hline Study identification & Comparison of treatments & Instruments \\
\hline \multicolumn{3}{|c|}{ Moderate and severe depression } \\
\hline Cook et $\left.a\right|^{26}$ & $\begin{array}{l}\text { Dialectic behavioural therapy vs } \\
\text { treatment as usual or no follow-up }\end{array}$ & $\begin{array}{l}\text { LPC, K-SADS-DRS* 'deliberate self-harm- } \\
\text { incidents per week' item, } \\
\text { CBCL 'deliberate self-harm' item, LPC self- } \\
\text { harm episodes per week }\end{array}$ \\
\hline Dalsbø et $a^{33}$ & $\begin{array}{l}\text { Combination treatment versus } \\
\text { psychological treatment }\end{array}$ & SIQ-Jr \\
\hline Socialstyrelsen ${ }^{25}$ & $\begin{array}{l}\text { Attachment-based family therapy versus } \\
\text { no follow-up }\end{array}$ & SIQ-Jr \\
\hline Socialstyrelsen ${ }^{25}$ & $\begin{array}{l}\text { Medical treatment versus psychological } \\
\text { treatment }\end{array}$ & Unclear \\
\hline
\end{tabular}

Serious and treatment resistant depression

\begin{tabular}{lll} 
Socialstyrelsen $^{25}$ & $\begin{array}{l}\text { Combination treatment versus } \\
\text { psychological treatment alone }\end{array}$ & SIQ-Jr \\
Socialstyrelsen $^{25}$ & Electroconvulsive therapy & Unclear \\
${\text { Donaldson et } \text { al }^{27}}^{\text {Transcranial magnetic stimulation }}$ & Unclear \\
\hline
\end{tabular}

*K-SADS-DRS is a subscale from the K-SADS-PL, a semistructured diagnostic interview to assess current and past episodes of psychopathology in children and adolescents.

CBCL, Child Behavior Checklist; LPC, Lifetime Parasuicide Cound; SIQ-Jr, Suicidal Ideation Questionnaire Junior High School.

researchers and providers may assume that psychological and psychosocial treatments are unlikely to have unwanted effects. As mentioned earlier, any intervention with potential beneficial effects, may also have negative or unwanted effects. ${ }^{8}$

Healthcare professionals should engage with their patients and their treatment decisions and expectations so that they can give meaningful and properly informed consent for their chosen treatment. ${ }^{35}$ This requires that children, young people and their next of kin are informed about the benefits and harms of available treatments, including any uncertainties. ${ }^{4}$ Such information should be communicated at an appropriate time, as part of a collaborative and supportive relationship with healthcare professionals. ${ }^{35}$

Based on the findings of this review, we suggest that researchers should identify potential unwanted effects of interventions and that evaluate these appropriately. Qualitative research or other input from patients and their carers may provide important insights identifying such consequences. ${ }^{36}$ Establishing core outcome sets covering what should be measured and reported in clinical trials should also be considered ${ }^{37}$ Furthermore, journals and funders should support the development of standards for evaluating potential unwanted effects of interventions.

\section{Strengths and limitations of this study}

We have applied transparent, systematic methods informed by the published principles for mapping reviews. By systematising existing literature and identifying gaps in the evidence base ${ }^{538}$ mapping reviews ${ }^{38}$ are an appropriate starting point for initiating new research and reviews. This review makes clear that a majority of the systematic reviews of treatments for depressed children and adolescents do not cover unwanted effects of treatments.

A limitation of overviews of systematic reviews such as this mapping study is that data extraction is done based on the reporting of results by the review authors and not on the primary studies. This means that the primary studies may have evaluated unwanted effects even though these were not reported in the reviews we included. However, whether the problem is at the primary study level or in the execution of systematic reviews, their absence in systematic reviews is of major importance because of the reliance now placed on systematic reviews by practitioners and those preparing information and guidelines for clinicians and families.

\section{CONCLUSION}

Knowledge of unwanted effects associated with treatments for depression in children and adolescents is inadequate. Most systematic reviews that have evaluated the effects of treatments for depression in children and adolescents do not report unwanted effects. Information about potentially unwanted effects of interventions should be more readily available to support informed decisions about choice of treatment and for patient safety. Qualitative research or other input from patients and their carers may provide important insights identifying such consequences. Establishing core outcome sets covering what should be measured and reported in clinical trials should also be considered. Furthermore, journals and funders should support the development of standards 
for evaluating potential unwanted effects of interventions in all protocols describing evaluations of treatments, including primary studies as well as systematic reviews.

Contributors $L M E$ and $A D$ assessed all relevant references and considered them for inclusion. All full-text reviews were assessed by LME and AD. LME, AD and ME performed data extraction and the descriptive analysis. LME drafted this manuscript and all authors provided substantial contribution to this process.

Funding The study was funded by Helsedirektoratet and RBUP Øst og Sør. Competing interests None declared.

Patient consent for publication Not required.

Provenance and peer review Not commissioned; externally peer reviewed.

Data availability statement All data relevant to the study are included in the article or uploaded as supplementary information.

Open access This is an open access article distributed in accordance with the Creative Commons Attribution Non Commercial (CC BY-NC 4.0) license, which permits others to distribute, remix, adapt, build upon this work non-commercially, and license their derivative works on different terms, provided the original work is properly cited, appropriate credit is given, any changes made indicated, and the use is non-commercial. See: http://creativecommons.org/licenses/by-nc/4.0/.

\section{ORCID iD}

Lise Mette Eidet http://orcid.org/0000-0003-1794-5281

\section{REFERENCES}

1 Fröhlich F. Network neuroscience. London, England: Academic Press, 2016.

2 Thapar A, Collishaw S, Pine DS, et al. Depression in adolescence. The Lancet 2012;379:1056-67.

3 Evans I, Thornton $\mathrm{H}$, Chalmers I, et al. Testing treatments. 2nd ed. London: Pinter and Martin, 2011.

4 Chalmers I, Atkinson P, Fenton M, et al. Tackling treatment uncertainties together: the evolution of the James Lind initiative, 2003-2013. J R Soc Med 2013;106:482-91.

5 Grant MJ, Booth A. A typology of reviews: an analysis of 14 review types and associated methodologies. Health Info Libr J 2009;26:91-108.

6 Dawes MG. On the need for evidence-based general and family practice. Evidence-Based Medicine 1996;1.

7 Tilson JK, Kaplan SL, Harris JL, et al. Sicily statement on classification and development of evidence-based practice learning assessment tools. BMC Med Educ 2011;11:78.

8 Chalmers I, Oxman AD, Austvoll-Dahlgren A, et al. Key concepts for informed health choices: a framework for helping people learn how to assess treatment claims and make informed choices. BMJ Evid Based Med 2018;23:29-33.

9 COMET Initiative. Taxonomy explanation and examples table, 2019. Available: http://www.comet-initiative.org/assets/downloads/ Taxonomy\%20explanation\%20table\%202018.10.30.pdf [Accessed 22 Feb 2019].

10 Vargesson N. Thalidomide-induced teratogenesis: history and mechanisms. Birth Defects Res C Embryo Today 2015;105:140-56.

11 Gilbert R, Salanti G, Harden M, et al. Infant sleeping position and the sudden infant death syndrome: systematic review of observational studies and historical review of recommendations from 1940 to 2002. Int $J$ Epidemiol 2005;34:874-87.

12 Petrosino A, Turpin-Petrosino C, Hollis-Peel ME, et al. Scared straight and other juvenile awareness programs for preventing juvenile delinquency: a systematic review. Campbell Systematic Reviews 2013:9:1-55.

13 Hawton K, Witt KG, Taylor Salisbury TL, et al. Interventions for self-harm in children and adolescents. Cochrane Database Syst Rev 2015;18.

14 Austvoll-Dahlgren A. Enabling informed treatment choices: development of an evidence portal for children and young people's mental health in Norway. Cochrane Colloquium, 2018.
15 Moher D, Liberati A, Tetzlaff J, et al. Preferred reporting items for systematic reviews and meta-analyses: the PRISMA statement. PLoS Med 2009;6:e1000097.

16 Shea BJ, Hamel C, Wells GA, et al. AMSTAR is a reliable and valid measurement tool to assess the methodological quality of systematic reviews. J Clin Epidemiol 2009;62:1013-20.

17 Higgins JPT, Green S, Cochrane C. Cochrane Handbook for systematic reviews of interventions. The Cochrane Collaboration: S.I, 2009.

18 Schünemann $\mathrm{H}$, Cochrane C. The GRADE Handbook, 2013.

19 RBUP Øst og Sør. Tilstandsgruppe: depresjon, in Håndbok for barn og unges psykiske helse: oppsummert forskning om effekt av tiltak. Oslo, Norway: Regional Centre for Child and Adolescent Mental Health, Eastern and Southern Norway, 2018.

20 RBUP Øst og Sør. IN SUM, Oppsummert forskning om tiltak for barn og unges psykiske helse og velferd. Oslo, Norway: Regional Centre for Child and Adolescent Mental Health, Eastern and Southern Norway, 2019. www.insum.no

21 Centre For Rreviews and Dissemination. The database of Abstracts of reviews of effects (DARE).. University of York, 2002.

22 GET-IT glossary. Adverse event, 2019. Available: https://getitglossary. org/term/adverse+event [Accessed 25 Dec 2019].

23 Keles S, Idsoe T. A meta-analysis of group cognitive behavioral therapy (CBT) interventions for adolescents with depression. $J$ Adolesc 2018;67:129-39.

24 Mychailyszyn MP, Elson DM. Working through the blues: a metaanalysis on interpersonal psychotherapy for depressed adolescents (IPT-A). Child Youth Serv Rev 2018;87:123-9.

25 Socialstyrelsen. Nationella riktlinjer för vård vid depression och ångestsyndrom. Stöd för styrning och ledning. Stockholm: Socialstyrelsen, 2017.

26 Cook NE, Gorraiz M, Nathan E. Dialectical behavior therapy for nonsuicidal self-injury and depression among adolescents: preliminary meta-analytic evidence. Child Adolesc Ment Health 2016;21:81-9.

27 Donaldson AE, Gordon MS, Melvin GA, et al. Addressing the needs of adolescents with treatment resistant depressive disorders: a systematic review of rTMS. Brain Stimul 2014;7:7-12.

28 Fleming TMet al. Serious games for the treatment or prevention of depression: a systematic review. Revista de Psicopatología y Psicología Clínica 2014;19:227-42.

29 Bailey AP, Hetrick SE, Rosenbaum S, et al. Treating depression with physical activity in adolescents and young adults: a systematic review and meta-analysis of randomised controlled trials. Psychol Med 2018;48:1068-83.

30 Aalbers S, Fusar-Poli L, Freeman RE, et al. Music therapy for depression. Cochrane Database Syst Rev 2017;11:Cd004517.

31 Meekums B, Karkou V, Nelson EA. Dance movement therapy for depression. Cochrane Database Syst Rev 2015:Cd009895.

32 Sharma T, Guski LS, Freund N, et al. Suicidality and aggression during antidepressant treatment: systematic review and metaanalyses based on clinical study reports. BMJ 2016;352:i65

33 Dalsbø TK, Siqveland J, Dahm KT, et al. Effekter av psykologisk terapi sammenlignet med antidepressive medikamenter alene eller i kombinasjon med psykologisk terapi for barn og unge med depresjon eller depresjonssymptomer: en systematisk oversikt. Folkehelseinstituttet, 2017.

34 Pu J, Zhou X, Liu L, et al. Efficacy and acceptability of interpersonal psychotherapy for depression in adolescents: a meta-analysis of randomized controlled trials. Psychiatry Res 2017;253:226-32.

35 NICE. Depression in children and young people: identification and management: Clinical Guideline [CG28], 2017. Available: https:// www.nice.org.uk/guidance/CG28

36 Alliance TJL. Top 10S of priorities for research, 2016. Available: http://www.jla.nihr.ac.uk/top-10-priorities/ [Accessed 27 Feb 2019].

37 COMET Initiative. Overview, 2019. Available: http://www.cometinitiative.org/about/overview [Accessed 27 Feb 2019].

38 Austvoll-Dahlgren A, Nsangi A, Semakula D. Interventions and assessment tools addressing key concepts people need to know to appraise claims about treatment effects: a systematic mapping review. Syst Rev 2016;5:215.

39 Tindall L, Mikocka-Walus A, McMillan D, et al. Is behavioural activation effective in the treatment of depression in young people? A systematic review and meta-analysis. Psychol Psychother 2017;90:770-96. 